\title{
Michael Shepherd: Founding Editor ${ }^{1}$
}

This issue marks the retirement from the editorship of the founder of Psychological Medicine, Professor Michael Shepherd. This editorial, by his successor, is a tribute to what he created.

Michael Shepherd started the journal in 1969. In several publications he has detailed its history, background and philosophy (Shepherd, 1986, 1990, 1992). With a not uncharacteristic mixture of the ironic smile and the serious conclusion, he claimed as the spirit in which it was launched:

Our initial task was to tackle three questions, namely the colour of the dust-jacket, an agreement on objectives, and a title. The first was easily resolved: since nothing in psychiatry is black or white, grey was evidently the colour of choice. With regard to objectives, we had thought originally of aiming at the education of professors of psychiatry: but their halo of omniscience appeared to be impenetrable, so we settled for the goal of indispensability by determining to concentrate on original, high-quality work across the wide spectrum of both psychiatry and its allied disciplines (Shepherd, 1986).

The meaning and origins of the title he discussed at length. Later, in an editorial (Shepherd, 1990) he listed among the more quantitative achievements, survival, a growing list of subscribers, a steady increase in size, high number of citations and citation impact factor, even a review in The Times Literary Supplement. At first published by the BMA, the journal has since 1976 had a congenial home with Cambridge University Press. Its steady growth, and impact from the beginning, have been widely recognized.

Judging a journal's quality, rather than quantity, is a complex business, and few would regard the most objective judge as the editor, old or new. Perhaps an incoming editor has a brief moment before the curtain of partiality fogs his vision. He may at least have recently tested his judgement on his more impartial friends. My little survey has confirmed what I had already thought. This is a journal of very high quality: scholarly, distinguished in its editorial board, careful and rigorous in its assessors, produced to a high standard, attentive to the best methodology, a home for first class research, broad in its scope, with contents that run from the hardest of neurobiological science, through the expected strengths in epidemiology, to the historical and the literary. The flavour has been unique, reflecting the unusual qualities of the man who was its editor. He formed it, shaped it, and even wrote most of the unsigned book reviews himself. He nurtured it with a powerful intellect and he gave it much time and care. In a distinguished academic and research career, with major influence in many directions, it is perhaps his greatest and most enduring creation.

Such hyperbole may dig a pit for his successors, but it is justified, and the new editorial team will try its best, with three new associate editors, and a largely unchanged Editorial Board. Some changes will come, as in any healthy institution they must, but they are for a little later. Continuity is high in our aims. Readers can judge in due course whether we succeed. Meanwhile to Michael Shepherd, the world of scholarly and scientific psychiatry owes much for what he has created. To him, our admiration and thanks.

EUGENE PAYKEL

\section{REFERENCES}

Shepherd M. (1986). Psychological medicine redivivus: concept and communication. Journal of the Royal Society of Medicine 79, 639-645.

Shepherd, M. (1990). Twenty years on. Psychological Medicine 20, 1-2.

${ }^{1}$ Address for correspondence: Professor Eugene Paykel, University of Cambridge, Department of Psychiatry, Addenbrooke's Hospital, Cambridge CB2 2QQ.

Shepherd, M. (1992). Psychiatric journals and the evolution of psychological medicine. Psychological Medicine 22, 15-25. 